\title{
Reported Barriers to Mental Health Care in Three Samples of U.S. Army National Guard Soldiers at Three Time Points
}

\author{
Marcia Valenstein, ${ }^{1,2}$ Lisa Gorman, ${ }^{3}$ Adrian J. Blow, ${ }^{4}$ Dara Ganoczy, ${ }^{1}$ Heather Walters, ${ }^{1}$ Michelle Kees, ${ }^{2}$ \\ Paul N. Pfeiffer, ${ }^{1,2}$ H. Myra Kim,,${ }^{1,5}$ Robert Lagrou, ${ }^{6}$ Shelley MacDermid Wadsworth, ${ }^{7}$ \\ Sheila A. M. Rauch, ${ }^{1,2}$ and Gregory W. Dalack ${ }^{2}$ \\ ${ }^{1}$ VA Center for Clinical Management Research, Ann Arbor Health Care System, Ann Arbor, Michigan, USA \\ ${ }^{2}$ University of Michigan Department of Psychiatry, Ann Arbor, Michigan, USA \\ ${ }^{3}$ Michigan Public Health Institute, Okemos, Michigan, USA \\ ${ }^{4}$ Department of Human Development and Family Studies, Michigan State University, East Lansing, Michigan, USA \\ ${ }^{5}$ Center for Statistical Consultation and Research, Ann Arbor, Michigan, USA \\ ${ }^{6}$ Henry Ford Kingsdale Hospital Ferndale, Michigan, USA \\ ${ }^{7}$ Military Family Research Institute, Purdue University, West Lafayette, Indiana, USA
}

\begin{abstract}
The military community and its partners have made vigorous efforts to address treatment barriers and increase appropriate mental health services use among returning National Guard soldiers. We assessed whether there were differences in reports of treatment barriers in 3 categories (stigma, logistics, or negative beliefs about treatment) in sequential cross-sectional samples of U.S. soldiers from a Midwestern Army National Guard Organization who were returning from overseas deployments. Data were collected during 3 time periods: September 2007-August 2008 ( $n=333$ ), March 2009-March $2010(n=884)$, and August 2011-August $2012(n=737)$. In analyses using discretized time periods and in trend analyses, the percentages of soldiers endorsing negative beliefs about treatment declined significantly across the 3 sequential samples $(19.1 \%, 13.9 \%$, and $11.1 \%)$. The percentages endorsing stigma barriers $(37.8 \%, 35.2 \%, 31.8 \%)$ decreased significantly only in trend analyses. Within the stigma category, endorsement of individual barriers regarding negative reactions to a soldier seeking treatment declined, but barriers related to concerns about career advancement did not. Negative treatment beliefs were associated with reduced services use $(O R=0.57 ; 95 \%$ CI $[0.33,0.97])$.
\end{abstract}

During the conflicts in Iraq and Afghanistan, the United States has deployed National Guard citizen-soldiers in numbers not seen since World War II (National Guard Bureau [NGB], n.d.; O'Neill, 2012). Army National Guard soldiers served beside active duty service members, but had different training experiences and unique challenges, including rapid transitions back to civilian life and employment upon their return home. National Guard soldiers often faced significant difficulties with

This work was supported by the U.S. Department of Veterans Affairs Health Services Research and Development Service, RRP 09-420 and SDP 10-047; the Welcome Back Veterans Initiative; the McCormick Foundation; and Families and Communities Together Coalition of Michigan State University. The authors gratefully acknowledge the men and women in the National Guard who participated in the study surveys in addition to Brigadier General (Retired) James Anderson, Brigadier General Burton K. Francisco, Captain Nicholas Anderson, and Staff Sergeant Patrick Wright. We also thank Ms. Jane Spinner and Mr. Brandon Brogan for their work with the Guard.

Correspondence concerning this article should be addressed to Marcia Valenstein, North Campus Research Complex, Building 16, 2800 Plymouth Road, Ann Arbor, MI 48109. E-mail: marciav@med.umich.edu

Published 2014. This article is a US Government work and is in the public domain in the USA. View this article online at wileyonlinelibrary.com DOI: $10.1002 /$ jts. 21942 reintegration and subsequently reported higher rates of posttraumatic stress disorder (PTSD) symptoms, depressive symptoms, and interpersonal difficulties following their return than have active component service members (Milliken, Auchterlonie, \& Hoge, 2007; Thomas et al., 2010). By 3 months following their return, $42.4 \%$ reported symptoms or psychosocial concerns warranting psychosocial evaluation or a continuation of mental health care (Milliken et al., 2007).

Unfortunately, National Guard soldiers' depressive and PTSD symptoms were also problematic at 12 months postreturn (Thomas et al., 2010), and many report financial and employment issues that place them at risk for the future development of mental health conditions (Riviere, Kendall-Robbins, McGurk, Castro, \& Hoge, 2011).

Of growing concern to the U.S. Department of Veterans Affairs (VA) and the Department of Defense (DoD), many returning soldiers with mental health symptoms do not initiate or stay in treatment long enough to receive evidence-based care (Milliken et al., 2007; Tanielian \& Jaycox, 2008). In one study, only $30.1 \%$ of soldiers who reported probable PTSD or major depression also reported receiving treatment that was likely to be of adequate duration and intensity (Tanielian \& Jaycox, 2008). 
Most evidence-based psychotherapies for depression and PTSD require multiple sessions. Yet, in the first year after a PTSD diagnosis in VA settings, only $9.5 \%$ of veterans received nine or more psychotherapy sessions in the VA health care system, suggesting few are receiving a full course of evidence-based treatment for PTSD (Seal et al., 2010).

In several studies, active duty soldiers and veterans have reported numerous barriers to accessing mental health care, including barriers related to stigma, practical logistical issues, and negative beliefs about treatment (Britt, 2000; Hoge et al., 2004; Vogt, 2011). Many studies have reported high levels of public stigma (the extent to which an individual believes others will devalue or reject him or her because of mental health issues or treatment; Britt, 2000; Hoge et al., 2004; Vogt, 2011). Studies have also reported substantial levels of logistical barriers such as securing an appointment, finding transportation, or covering the costs of care (Britt, 2000; Pietrzak, Johnson, Goldstein, Malley, \& Southwick, 2009) in addition to high levels of negative treatment beliefs, such as concerns that mental health treatments do not work (Pietrzak et al., 2009).

As noted below, the DoD, the Army, the NGB, and the VA have developed multiple programs to assist returning National Guard soldiers with reintegration challenges and with securing mental health services when needed (Bowles \& Bates, 2010; Cornum, Matthews, \& Seligman, 2011; Yellow Ribbon Reintegration Program, 2013). For example, the NGB has appointed directors of psychological health for each state and territory and National Guard soldiers are able to participate in the legislatively mandated Yellow Ribbon Reintegration Program as well as the Army's Comprehensive Soldier and Family Fitness program. In addition, some states have instituted peer outreach programs, such as Buddy-to-Buddy in Michigan and Warrior to Warrior in Illinois as reintegration services (Greden et al., 2010; Yellow Ribbon Reintegration Program, 2013). Over time, these activities and efforts may have impacted organizational culture, soldiers' beliefs regarding mental health conditions and treatment, and reduced perceived barriers to care.

To date, most studies of National Guard service members have examined barriers to mental health care cross sectionally at one time point and do not provide insights into possible changes in perceived barriers among newly returning soldiers over time (Pietrzak et al., 2009). One prior study did examine barriers to care cross sectionally in two separate samples of National Guard soldiers at 3 months and at 12 months postreturn, but found no difference in reports of stigma and other care barriers at these time points (Kim, Thomas, Wilk, Castro, \& Hoge, 2010). There has been no assessment, however, of reported barriers within sequential cohorts of newly returning soldiers within the same National Guard organization to assess potential changes in perceptions within a National Guard population over multiple years.

This study presents data collected from three separate samples of National Guard soldiers from the same state National Guard organization within 6 months of their return from overseas deployments. In time periods just before and following the return of these soldier cohorts, multiple programs to reduce treatment barriers were initiated or expanded in this National Guard organization. These efforts started with consistent mental health professional presence at National Guard reintegration events, continued with the start and expansion of a veteran peer-outreach program, implementation of Army-wide suicide prevention stand-downs, and resiliency-training efforts. These activities and efforts may have impacted organizational culture and soldiers' beliefs regarding mental health conditions and treatment since the first sample of soldiers in this National Guard organization was studied by Gorman and colleagues in 2007-2008 (Gorman, Blow, Ames, \& Reed, 2011).

We assessed whether there were differences in the percentages of National Guard soldiers reporting barriers related to stigma, logistical issues, or negative beliefs about treatment in the three sequential samples. We hypothesized that given multiple efforts and programs to reduce barriers to appropriate treatment, reports of treatment barriers would be lower in National Guard soldiers returning at later dates. We also assessed associations between soldiers' demographics and mental health symptoms and their reports of treatment barriers, and explored the relationship between reported barriers and mental health services use among soldiers who had symptoms.

\section{Method}

We conducted a trend study of National Guard soldiers where the three soldier samples (described below) were from the population of interest, but not composed of the same people. Trend studies are common in the epidemiologic literature and in mental health services research (Olfson et al., 2002; Pfeiffer, Szymanski, Valenstein, McCarthy, \& Zivin, 2012; Schneider et al., 2003).

\section{Participants and Procedure}

Survey participants were recruited from returning National Guard soldiers who returned during 3 time periods (T1: September 2007-August 2008, $n=333$; T2: March 2009-March 2010, $n=884$; and T3: August 2011-August 2012, $n=737$ ). The Michigan State University Institutional Review Board (IRB) approved data collection for the first cohort of soldiers. The University of Michigan and Michigan State University IRBs approved data collection for the second cohort of soldiers, and the U.S. Department of Veterans Affairs Ann Arbor Health System approved data collection for the third cohort of soldiers.

Participants who returned during the first two time periods (T1 and T2) were recruited during reintegration weekends, which took place approximately 45-90 days following the soldiers' return from their overseas deployments. Participants in these two time periods completed a voluntary and anonymous survey during a nonscheduled portion of the reintegration weekend.

Survey participants in the third time period (T3) were recruited approximately 6 months following their return from 
overseas deployments. They were recruited in person during monthly drill weekends and by mail using a slightly modified version of the Dillman method (Dillman, Smyth, \& Christian, 2009). During drill weekends, a member of the study team would brief the soldiers, describing the survey. Team members would distribute the survey packets (which included questionnaires used in study measures) and remain on site for several hours to collect completed surveys. Surveys that were not distributed during drill weekends were sent via mail, with up to two additional follow-up mailings being sent to nonrespondents.

Soldiers in the first time period received a $\$ 10$ gift card incentive and the response rate was $40.3 \%(n=333)$. Soldiers in the second time period received an incentive of $\$ 25$ and the response rate was $72.3 \%(n=884)$, and soldiers in the third time period received a $\$ 50$ gift card incentive and the response rate was $49.0 \%(n=737)$.

The overall soldier sample $(N=1,954)$ was primarily male $(89.2 \%)$, aged 30 years or below $(46.6 \%)$, and predominantly White $(82.4 \%)$. The majority of soldiers $(54.2 \%)$ had some postsecondary education but no bachelor's degree, whereas $19.9 \%$ had a bachelor's degree or more (Table 1).

\section{Measures}

The primary outcome measures were barriers to treatment assessed using the Hoge adaptation of the Perceived Stigma and Barriers to Care measure (Hoge et al., 2004; Vogt, 2011). In our factor analyses of study data evaluating 16 barrier items using varimax rotation, we identified three principal factors: a 7 -item stigma factor, a 7-item logistics factor, and a 2-item factor regarding negative beliefs about mental health treatment. Study factors were similar to those identified or used in prior studies that used the Hoge adaptation (Kehle et al., 2010; Wright et al., 2009). Eigenvalues were 5.10 for the stigma, 3.78 for the logistics, and 1.26 for the beliefs factors. Items within each factor loaded at .50 level or higher, and Cronbach's $\alpha$ for the stigma, logistics, and beliefs categories were .95, .88, and .75, respectively.

As in prior studies (Hoge et al., 2004), soldiers were considered to have endorsed an individual barrier to care if they indicated that they agreed or strongly agreed with the item assessing this barrier. Soldiers were considered to have endorsed the stigma, logistics, or beliefs categories if they agreed or strongly agreed with any of the items within these categories (See Table 2 for items comprising each barrier category.)

The presence or absence of clinically significant depressive symptoms was assessed with the Beck Depression InventoryII (BDI-II) in the cohort returning during the first time period and the Patient Health Questionnaire (PHQ-9) in the cohorts returning during the second and third time periods. The time frame for completing both the BDI-II and the PHQ-9 was the past 2 weeks. The BDI-II has been widely used to assess the severity of depressive symptoms and has shown high levels of reliability (Arnau, Meagher, Norris, \& Bramson, 2001; Steer \& Clark, 1997). In our study sample at T1, the Cronbach's $\alpha$ for the BDI-II was .91 . Soldiers were considered to have significant depressive symptoms if they scored $\geq 14$ on the BDIII, indicating a significant level of depressive symptoms (Beck, Steer, \& Brown, 1996). The PHQ-9 assesses nine symptoms of depression listed in the Diagnostic and Statistical Manual of Mental Disorders (4th ed., DSM-IV; American Psychiatric Association, 1994) over a 2-week period. In our samples at T2 and T3, the Cronbach's $\alpha$ for the PHQ-9 was .89 and .91, respectively. The PHQ-9 has sensitivity of $88 \%$ and a specificity of $88 \%$ for major depression at scores $>10$ (Kroenke, Spitzer, \& Williams, 2001), and soldiers in this sample were considered to have significant depressive symptoms if their PHQ-9 scores were $\geq 10$.

In all three time periods, PTSD symptoms were measured using the Posttraumatic Stress Disorder Checklist-Military Version (PCL-M) a self-report measure of the 17 DSM-IV PTSD symptoms. Respondents rated how much they were bothered by the specified problem on a 5-point scale ranging from 1 $=$ not at all to $5=$ all the time in response to stressful military experiences. The PCL-M has excellent internal consistency and is correlated with other PTSD measures (Blanchard, Jones Alexander, Buckley, \& Forneris, 1996; Bliese et al., 2008). In our sample, the Cronbach's $\alpha$ for the PCL-M were $.95, .96$, and .97 , at $\mathrm{T} 1, \mathrm{~T} 2$, and $\mathrm{T} 3$, respectively. Soldiers were considered to have significant PTSD symptoms if PCL-M scores were $\geq$ 50 (Weathers, Litz, Herman, Huska, \& Keane, 1993).

For the first two time periods, hazardous alcohol use was determined using the first three items of the Alcohol Use Disorders Identification Test (AUDIT; Reinert \& Allen, 2007), on which the shorter Alcohol Use Disorders Identification TestConsumption scale (AUDIT-C) is based. For the third time period, the AUDIT-C was used (Babor \& Kadden, 2005; Bradley et al., 2007). The AUDIT-C has previously shown high levels of internal consistency, test-retest reliability, and accuracy in identifying at-risk use (Bradley et al., 2007). In our sample, the Cronbach's $\alpha$ for the first three AUDIT questions assessing frequency and quantity of alcohol use were .82 for $\mathrm{T} 1$ and .88 for T2. The Cronbach's $\alpha$ for the AUDIT-C was .69 at T3. Cutoff scores for risky drinking on the AUDIT and AUDIT-C were designated as 3 or more for women and 4 or more for men. Another study using these cutoffs resulted in a sensitivity and specificity for risky drinking for women of $93.6 \%$ and $79.5 \%$, respectively, and a sensitivity and specificity for risky drinking for men of $99.0 \%$ and $79.1 \%$, respectively (Dawson, Grant, Stinson, \& Zhou, 2005).

National Guard soldiers were considered to have received mental health services if they endorsed any of 14 survey items asking about the receipt of mental health services for a stress, emotional, alcohol, or family problem from either general medical or mental health providers in a variety of settings (military, civilian, VA clinics, or in vet centers) in the last year. The question format used was "In the past, have you received mental health services for a stress, emotional, or family problem from: [specified provider] with response items of "No," "Yes, in the last year," or "Yes, but more than a year ago." 
Table 1

Demographic Characteristics and Comparisons Across Three Time Periods

\begin{tabular}{|c|c|c|c|c|c|c|c|c|c|}
\hline \multirow[b]{2}{*}{ Variable } & \multicolumn{2}{|c|}{$\begin{array}{c}\text { Overall } \\
(n=1,954)\end{array}$} & \multicolumn{2}{|c|}{$\begin{array}{l}\text { T1 2007-2008 } \\
\quad(n=333)\end{array}$} & \multicolumn{2}{|c|}{$\begin{array}{c}\mathrm{T} 22009-2010 \\
(n=884)\end{array}$} & \multicolumn{2}{|c|}{$\begin{array}{c}\text { T3 2011-2012 } \\
(n=737)\end{array}$} & \multirow[b]{2}{*}{$x^{2}$} \\
\hline & $n$ & $\%$ & $n$ & $\%$ & $n$ & $\%$ & $n$ & $\%$ & \\
\hline \multicolumn{10}{|l|}{ Sex } \\
\hline Female & 207 & 10.8 & 44 & 13.5 & 80 & 9.3 & 83 & 11.4 & \\
\hline Male & 1,711 & 89.2 & 283 & 86.5 & 780 & 90.7 & 648 & 88.7 & \\
\hline Age group (years) & & & & & & & & & $104.54^{* * *}$ \\
\hline $18-21$ & 175 & 9.0 & 16 & 4.8 & 122 & 13.9 & 37 & 5.1 & \\
\hline $22-30$ & 727 & 37.5 & 93 & 27.9 & 369 & 42.2 & 265 & 36.4 & \\
\hline $31-40$ & 520 & 26.8 & 101 & 30.3 & 224 & 25.6 & 195 & 26.8 & \\
\hline $41-50$ & 428 & 22.1 & 103 & 30.9 & 139 & 15.9 & 186 & 25.5 & \\
\hline$\geq 51$ & 87 & 4.5 & 20 & 6.0 & 21 & 2.4 & 46 & 6.3 & \\
\hline White & & & & & & & & & $6.97^{*}$ \\
\hline Yes & 1,512 & 82.4 & 264 & 79.8 & 661 & 85.1 & 587 & 80.6 & \\
\hline No & 324 & 17.7 & 67 & 20.2 & 116 & 14.9 & 141 & 19.4 & \\
\hline Education & & & & & & & & & $38.13^{* * * *}$ \\
\hline HS/GED & 497 & 25.9 & 55 & 16.5 & 260 & 30.5 & 182 & 24.9 & \\
\hline Some college & 1,039 & 54.2 & 185 & 55.6 & 460 & 53.9 & 394 & 53.8 & \\
\hline Bachelors + & 382 & 19.9 & 93 & 27.9 & 133 & 15.6 & 156 & 21.3 & \\
\hline Military rank & & & & & & & & & $47.81^{* * *}$ \\
\hline Junior enlisted & 798 & 41.9 & 102 & 30.7 & 412 & 49.1 & 284 & 38.7 & \\
\hline Senior enlisted & 855 & 44.9 & 168 & 50.6 & 351 & 41.8 & 336 & 45.8 & \\
\hline Officers & 252 & 13.2 & 62 & 18.7 & 76 & 9.1 & 114 & 15.5 & \\
\hline MH symptoms PTSD & & & & & & & & & 5.21 \\
\hline Yes & 250 & 13.5 & 37 & 11.5 & 103 & 12.4 & 110 & 15.8 & \\
\hline No & 1,598 & 86.5 & 286 & 88.5 & 727 & 87.6 & 585 & 84.2 & \\
\hline Depression & & & & & & & & & $7.16^{*}$ \\
\hline Yes & 421 & 21.8 & 69 & 20.7 & 213 & 24.5 & 139 & 19.0 & \\
\hline No & 1,514 & 78.2 & 264 & 79.3 & 658 & 75.6 & 592 & 81.0 & \\
\hline PTSD/Depression & & & & & & & & & 5.21 \\
\hline Yes & 489 & 25.2 & 78 & 23.4 & 242 & 27.7 & 169 & 23.0 & \\
\hline No & 1,453 & 74.8 & 255 & 76.6 & 633 & 72.3 & 565 & 77.0 & \\
\hline Risky alcohol & & & & & & & & & $19.91^{* * * *}$ \\
\hline Yes & 1,013 & 53.2 & 153 & 46.4 & 497 & 58.8 & 363 & 49.9 & \\
\hline No & 891 & 46.8 & 177 & 53.6 & 349 & 41.3 & 365 & 50.1 & \\
\hline
\end{tabular}

Note. Please note that soldiers included in each individual analysis do not always equal the full complement of soldiers because of deletion of individuals with missing data for that variable. $\mathrm{HS}=$ high school; GED = general education degree; $\mathrm{MH}=$ mental health; PTSD = posttraumatic stress disorder.

$* p<.05$. ** $p<.01$. *** $p<.001$.

\section{Data Analysis}

The primary independent variable was time period of survey data collection for each of the three samples. Covariates in multivariable analyses included age group, sex, race/ethnicity, education, and military rank as determined by soldiers' responses to demographic items on the survey.

Descriptive analyses were completed for the study sample using means or frequencies as indicated. Bivariate analyses were completed using $\chi^{2}$ tests to compare baseline characteristics of the three sequential samples. Both $\chi^{2}$ tests and the Cochran-Armitage Trend Test were used to assess changes in the endorsement of barrier categories across the three samples (Cochran, 1954).

Separate logistic regression analyses were completed to assess the relationships between the dependent variables of negative beliefs about mental health treatment, stigma, and logistical barriers and the primary predictor of sample time period. Time period was modeled in three ways. First, time period was modeled using dummy variables, with the first time period as the reference. Second, time was entered as interval data $(0,1$, and 2). Finally, to account for the differential time frames between returning cohorts, time was included as the number of months 
Table 2

Barriers to Care and Comparisons Across Three Time Periods

\begin{tabular}{|c|c|c|c|c|c|c|c|c|c|c|}
\hline \multirow[b]{2}{*}{ Variable } & \multicolumn{2}{|c|}{$\begin{array}{c}\text { Overall } \\
(n=1,954)\end{array}$} & \multicolumn{2}{|c|}{$\begin{array}{c}\text { T1 } \\
2007-2008 \\
(n=333)\end{array}$} & \multicolumn{2}{|c|}{$\begin{array}{c}\mathrm{T} 2 \\
2009-2010 \\
(n=884)\end{array}$} & \multicolumn{2}{|c|}{$\begin{array}{c}\text { T3 } \\
2011-2012 \\
(n=737)\end{array}$} & \multirow[b]{2}{*}{$x^{2}$} & \multirow[b]{2}{*}{$z^{\mathrm{a}}$} \\
\hline & $n$ & $\%$ & $n$ & $\%$ & $n$ & $\%$ & $n$ & $\%$ & & \\
\hline \multicolumn{11}{|l|}{$\overline{\text { Stigma }}$} \\
\hline Too embarrassing & & & & & & & & & 4.41 & 1.80 \\
\hline Yes & 258 & 13.7 & 49 & 14.9 & 126 & 15.1 & 83 & 11.6 & & \\
\hline No & 1623 & 86.3 & 279 & 85.1 & 711 & 85.0 & 633 & 88.4 & & \\
\hline Harm career & & & & & & & & & 1.18 & 0.97 \\
\hline Yes & 300 & 16.0 & 55 & 16.8 & 139 & 16.7 & 106 & 14.8 & & \\
\hline No & 1578 & 84.0 & 273 & 83.2 & 695 & 83.3 & 610 & 85.2 & & \\
\hline Unit members have less confidence in me & & & & & & & & & $9.99^{* *}$ & $3.16^{* *}$ \\
\hline Yes & 263 & 14.2 & 61 & 18.7 & 120 & 14.8 & 82 & 11.5 & & \\
\hline No & 1593 & 85.8 & 266 & 81.4 & 693 & 85.2 & 634 & 88.6 & & \\
\hline Unit leadership treats me differently & & & & & & & & & $7.05^{*}$ & $2.61^{* *}$ \\
\hline Yes & 294 & 15.8 & 62 & 19.0 & 138 & 16.9 & 94 & 13.1 & & \\
\hline No & 1565 & 84.2 & 265 & 81.0 & 678 & 83.1 & 622 & 86.9 & & \\
\hline Leaders blame me & & & & & & & & & $6.42^{*}$ & $2.48^{*}$ \\
\hline Yes & 153 & 8.2 & 37 & 11.4 & 68 & 8.3 & 48 & 6.7 & & \\
\hline No & 1705 & 91.8 & 289 & 88.7 & 748 & 91.7 & 668 & 93.3 & & \\
\hline Seen as weak & & & & & & & & & $9.12^{*}$ & $3.00^{* *}$ \\
\hline Yes & 269 & 14.3 & 59 & 18.0 & 128 & 15.3 & 82 & 11.5 & & \\
\hline No & 1612 & 85.7 & 268 & 82.0 & 710 & 84.7 & 634 & 88.6 & & \\
\hline Don't want it in military records & & & & & & & & & 3.04 & 1.31 \\
\hline Yes & 502 & 27.0 & 101 & 30.9 & 213 & 26.1 & 188 & 26.3 & & \\
\hline No & 1357 & 73.0 & 226 & 69.1 & 603 & 73.9 & 528 & 73.7 & & \\
\hline Any stigma item & & & & & & & & & 4.00 & $1.99^{*}$ \\
\hline Yes & 647 & 34.4 & 124 & 37.8 & 295 & 35.2 & 228 & 31.8 & & \\
\hline No & 1235 & 65.6 & 204 & 62.2 & 543 & 64.8 & 488 & 68.2 & & \\
\hline \multicolumn{11}{|l|}{ Logistical } \\
\hline Where to get help? & & & & & & & & & 0.29 & 0.48 \\
\hline Yes & 104 & 5.5 & 19 & 5.8 & 48 & 5.7 & 37 & 5.2 & & \\
\hline No & 1780 & 94.5 & 310 & 94.2 & 790 & 93.3 & 680 & 94.8 & & \\
\hline Inadequate transport & & & & & & & & & 2.84 & 1.67 \\
\hline Yes & 72 & 3.8 & 17 & 5.2 & 33 & 4.0 & 22 & 3.1 & & \\
\hline No & 1803 & 96.2 & 309 & 94.8 & 800 & 96.0 & 694 & 96.9 & & \\
\hline Difficult to schedule & & & & & & & & & 19.66 & -1.52 \\
\hline Yes & 188 & 10.0 & 40 & 12.2 & 55 & 6.6 & 93 & 13.0 & & \\
\hline No & 1691 & 90.0 & 288 & 87.8 & 780 & 93.4 & 623 & 87.0 & & \\
\hline Getting time off work & & & & & & & & & 12.86 & -0.18 \\
\hline Yes & 205 & 10.9 & 47 & 14.4 & 67 & 8.0 & 91 & 12.7 & & \\
\hline No & 1676 & 89.1 & 280 & 85.6 & 772 & 92.0 & 624 & 87.3 & & \\
\hline Care costs too much money & & & & & & & & & 1.14 & 0.00 \\
\hline Yes & 307 & 16.4 & 57 & 17.7 & 129 & 15.4 & 121 & 17.0 & & \\
\hline No & 1568 & 83.6 & 266 & 82.4 & 709 & 84.6 & 593 & 83.1 & & \\
\hline No providers available & & & & & & & & & 1.57 & 0.76 \\
\hline Yes & 87 & 4.6 & 15 & 4.6 & 44 & 5.3 & 28 & 3.9 & & \\
\hline No & 1792 & 95.4 & 312 & 95.4 & 793 & 94.7 & 687 & 96.1 & & \\
\hline Long distances to care & & & & & & & & & 3.87 & -0.62 \\
\hline Yes & 154 & 8.2 & 30 & 9.2 & 57 & 6.8 & 67 & 9.4 & & \\
\hline
\end{tabular}


Table 2

Continued

\begin{tabular}{|c|c|c|c|c|c|c|c|c|c|c|}
\hline \multirow[b]{2}{*}{ Variable } & \multicolumn{2}{|c|}{$\begin{array}{c}\text { Overall } \\
(n=1,954)\end{array}$} & \multicolumn{2}{|c|}{$\begin{array}{c}\mathrm{T} 1 \\
2007-2008 \\
(n=333)\end{array}$} & \multicolumn{2}{|c|}{$\begin{array}{c}\mathrm{T} 2 \\
2009-2010 \\
(n=884)\end{array}$} & \multicolumn{2}{|c|}{$\begin{array}{c}\text { T3 } \\
2011-2012 \\
(n=737)\end{array}$} & \multirow[b]{2}{*}{$x^{2}$} & \multirow[b]{2}{*}{$z^{\mathrm{a}}$} \\
\hline & $n$ & $\%$ & $n$ & $\%$ & $n$ & $\%$ & $n$ & $\%$ & & \\
\hline No & 1727 & 91.8 & 298 & 90.9 & 781 & 93.2 & 648 & 90.6 & & \\
\hline $\begin{array}{l}\text { Any logistical item } \\
\text { Yes } \\
\text { No }\end{array}$ & $\begin{array}{r}581 \\
1305\end{array}$ & $\begin{array}{l}30.8 \\
69.2\end{array}$ & $\begin{array}{l}115 \\
215\end{array}$ & $\begin{array}{l}34.9 \\
65.2\end{array}$ & $\begin{array}{l}228 \\
611\end{array}$ & $\begin{array}{l}27.2 \\
72.8\end{array}$ & $\begin{array}{l}238 \\
479\end{array}$ & $\begin{array}{l}33.2 \\
66.8\end{array}$ & $9.64^{\text {** }}$ & -0.26 \\
\hline Belief & & & & & & & & & & \\
\hline $\begin{array}{l}\text { Don't trust MHPs } \\
\text { Yes } \\
\text { No }\end{array}$ & $\begin{array}{r}208 \\
1679\end{array}$ & $\begin{array}{l}11.0 \\
89.0\end{array}$ & $\begin{array}{r}54 \\
276\end{array}$ & $\begin{array}{l}16.4 \\
83.6\end{array}$ & $\begin{array}{r}93 \\
746\end{array}$ & $\begin{array}{l}11.1 \\
88.9\end{array}$ & $\begin{array}{r}61 \\
657\end{array}$ & $\begin{array}{r}8.5 \\
91.5\end{array}$ & 14.28 & $3.67^{* * *}$ \\
\hline $\begin{array}{l}\text { MH care doesn't work } \\
\text { Yes } \\
\text { No }\end{array}$ & $\begin{array}{r}122 \\
1756\end{array}$ & $\begin{array}{r}6.5 \\
93.5\end{array}$ & $\begin{array}{r}25 \\
302\end{array}$ & $\begin{array}{r}7.7 \\
92.4\end{array}$ & $\begin{array}{r}54 \\
781\end{array}$ & $\begin{array}{r}6.5 \\
93.5\end{array}$ & $\begin{array}{r}43 \\
673\end{array}$ & $\begin{array}{r}6.0 \\
94.0\end{array}$ & 1.00 & 0.95 \\
\hline $\begin{array}{l}\text { Endorsed any belief item } \\
\text { Yes } \\
\text { No }\end{array}$ & $\begin{array}{r}260 \\
1627\end{array}$ & $\begin{array}{l}13.8 \\
86.2\end{array}$ & $\begin{array}{r}63 \\
267\end{array}$ & $\begin{array}{l}19.1 \\
80.9\end{array}$ & $\begin{array}{l}117 \\
722\end{array}$ & $\begin{array}{l}14.0 \\
86.1\end{array}$ & $\begin{array}{r}80 \\
638\end{array}$ & $\begin{array}{l}11.1 \\
88.9\end{array}$ & 12.06 & $3.40^{* * *}$ \\
\hline
\end{tabular}

Note. The number of soldiers included in each individual analysis does not always equal the full complement of soldiers because of deletion of individuals with missing data for that variable. MHP = military health provider; $\mathrm{MH}=$ mental health.

${ }^{\mathrm{a}}$ Cochrane-Armitage Trend Test.

$* p<.05 . * * p<.01 . * * * p<.001$.

since the beginning of data collection for consecutive cohorts $(0,18$, and 29 months).

All multivariable models included age, gender, race, military rank, education, the presence of significant PTSD symptoms, presence of significant levels of depressive symptoms, and presence of hazardous alcohol use.

Finally, in the subgroup of soldier from all three groups with significant mental health symptoms, an exploratory logistic regression analysis was conducted to assess the relationship between the dependent variable of any mental health services use in the last year and the independent variables of endorsement of barrier categories (stigma, logistics, or negative beliefs about treatment). This analysis also included cohort time period, age, gender, education, race, rank, whether soldiers had PTSD symptoms alone, depressive symptoms alone, or a combination of PTSD and depressive symptoms in the model. All analyses were completed using SAS software, version 9.3.

\section{Results}

As presented in Table 1, approximately $13.5 \%$ of the soldiers in the sample reported clinically significant PTSD symptoms and $21.8 \%$ reported clinically significant levels of depressive symptoms. Soldiers also reported high rates of hazardous alcohol use (Table 1).

The samples differed significantly in age, race, rank, and level of education. They also differed on levels of depressive symptoms and risky drinking, but did not differ on PTSD symptoms or combined mental health symptoms. In the overall sample,
$49.2 \%$ of soldiers reported at least one significant barrier to care, with $34.4 \%$ reporting a barrier related to stigma, 30.8\% a barrier related to logistics, and $13.8 \%$ a barrier related to negative beliefs about treatment.

The most commonly endorsed individual barrier across all three samples was an item in the stigma category, a concern about having mental health treatment appear in one's military records (endorsed by $27.0 \%$ of respondents). As shown in Table 2, four other items in the stigma category were among the more commonly endorsed barriers, including concerns about harming one's career, being treated differently by unit leadership, being seen as weak, and losing the confidence of other unit members. One item in the logistics category, mental health treatment costing too much, was also among the more commonly endorsed individual barriers.

Bivariate analyses indicated significant differences by time period in the percentages of soldiers endorsing a barrier related to logistics or negative beliefs about treatment, but not in the percentages endorsing a barrier related to stigma. The CochranArmitage test for trend indicated a significant decreasing trend in the percentages endorsing a barrier related to negative beliefs about mental health treatment $(z=3.40, p<.001)$ or a barrier related to stigma $(z=1.99, p=.046)$ over the three consecutive time periods. Endorsement of barriers related to logistics did not show a consistent trend, with a lower percentage of soldiers reporting a logistical barrier at $\mathrm{T} 2$ than at either $\mathrm{T} 1$ or $\mathrm{T} 3$.

In logistic regression analyses, with study time period coded as dummy variables, time was significantly associated with the report of a barrier due to negative beliefs about treatment or 
logistics (Supplemental Data Table 1). Compared to soldiers in the first time period, soldiers in the second and third time periods were significantly less likely to report any barrier due to negative treatment beliefs, and soldiers in the second time period were less likely to report any barriers related to logistics of accessing care.

When time period was considered as an interval variable, time was significantly associated with decreased reports of negative beliefs about treatment (Estimate $=-0.35$, standard error $[S E]=0.10, p<.001)$ and with decreased reports of stigma barriers (Estimate $=-0.16, S E=0.07, p=.030$ ). When time was entered as months since the start of data collection for consecutive cohorts, results were similar, with a significant reduction in the three samples returning over time in stigma barriers (Estimate $=-0.12, S E=0.06, p=.047$ ) and in belief barriers (Estimate $=-0.31, S E=0.08, p<.001)$.

In bivariate analyses, many but not all individual barrier items within the three barrier categories differed with time period. Four of the seven individual stigma items showed both significant differences in $\chi^{2}$ tests and a significant downward trend with the Cochran-Armitage test. Stigma items that declined over time primarily elicited concerns regarding others' devaluation of an individual seeking mental health treatment and included "members of my unit might have less confidence in me," "unit leadership might treat me differently," "my leaders would blame me for the problem," and "I would be seen as weak." Stigma-related concerns about having mental health treatment appearing in one's medical records or about it harming one's career advancement did not decrease significantly over time.

One individual item in the belief scale, "I don't trust mental health professionals" showed significant differences by time period and a significant downward trend over the three consecutive time periods. The belief that "mental health care doesn't work" was endorsed relatively infrequently and did not show a significant change over the time periods.

Across the panel samples, age, gender, and race were not related to stigma barriers. General officers were more likely than junior enlisted soldiers to endorse stigma barriers. Soldiers in several older age groups (22-30 years, 31-40 years, and 4150 years) were less likely to endorse negative beliefs about treatment than younger soldiers (18-21 years). Soldiers with high levels of PTSD and depressive symptoms were more likely to endorse all three categories of treatment barriers than soldiers with lower levels of symptoms (Supplemental Data Table 1).

Across all panel samples, $51.7 \%$ of returning National Guard soldiers with mental health symptoms used mental health services in the last year. Approximately $56.4 \%$ of soldiers with symptoms in the first time period, $39.7 \%$ in the second time period, and $66.1 \%$ in the third time period reported having used mental health services. In the subgroup of soldiers with mental health symptoms, the endorsement of barriers related to negative beliefs about treatment was associated with reduced services use. Barriers related to stigma or logistics were not significantly associated with services use (Supplemental Data Table 2).

\section{Discussion}

As in prior studies of active component and Guard soldiers (Milliken et al., 2007; Pietrzak et al., 2009), soldiers in this midwestern Guard organization reported high rates of mental health symptoms and there were potential "gaps" in treatment engagement. Across all study time periods, approximately $25.2 \%$ reported significant mental health symptoms; however, only $51.7 \%$ of those with significant symptoms reported receiving mental health services in the prior year.

Also as in prior studies (Pietrzak et al., 2009), soldiers often reported barriers to engaging in care, potentially accounting for the observed gaps in treatment engagement. Stigma barriers were most frequently reported (34.4\%), followed by logistical barriers $(30.8 \%)$ and then barriers related to negative beliefs about treatment $(13.8 \%)$. We note that individual items were endorsed at lower rates by this National Guard population than by active component service members in 2004 (Hoge et al., 2004), but were endorsed at similar rates by National Guard population in 2003 and 2007 (Kim et al., 2010).

Of primary interest in this study was our finding regarding differences in reports of treatment barriers among soldiers in the three consecutively returning samples (2007-2008, 2009-2010, and 2011-2012). In multivariate analyses using dummy variables for time/sample, reports of negative beliefs about treatment were significantly lower in the second and third time periods compared to the first. Negative beliefs about treatment also decreased significantly when time was coded either as an interval variable or as months between periods of data collection for the samples. In analyses using dummy variables, logistical barriers were reported significantly less often in the second time period compared to the first but did not show consistent reductions when time was coded as an interval variable or as months between periods of data collection. Finally, when time/sample was coded as dummy variables, stigma barriers did not differ significantly in the first compared to the second or third time periods, but did decrease significantly when time was coded as an interval variable or as months between data collection periods.

In secondary analyses, the four individual stigma items that showed significant differences over time primarily elicited concerns regarding whether others would devalue or treat a soldier differently if she or he sought treatment and included such items as "members of my unit might have less confidence in me" or "my leaders would blame me for the problem." Stigma items, however, that assessed concerns about documentation of treatment in the medical record and the impact of treatment on one's career advancement did not change significantly over time. Potentially, concerns regarding career impact may be based on repercussions that still occur in the military when one seeks mental health treatment (e.g., delayed or denied security clearances, delays in promotion, limitations in occupational specialty). This suggests that efforts 
to reduce actual repercussions in career advancement in addition to efforts to reduce stigma-related misperceptions need to continue.

This constitutes the first report of which we are aware of significant reductions in barriers related to negative beliefs about treatment and to individual barriers due to stigma in a National Guard Organization. In a prior study, Kim et al. (2010) found no changes in barriers related to stigma in cross-sectional samples conducted 3 and 12 months following National Guard and active component service members' return from deployments (Kim et al., 2010); however, their study data were collected between 2003 and 2007 when many efforts to reduce treatment barriers were just beginning.

Barriers to care, particularly those related to stigma, have received considerable attention more recently as policy makers and clinicians have considered gaps in treatment among returning soldiers with mental health symptoms. The DoD, Army, National Guard, and the VA have developed and implemented multiple programs to assist returning soldiers with reintegration challenges and have worked to reduce the stigma associated with mental health treatment. In this observational study, cause and effect and the impact of specific programs cannot be assessed; however, the observed decreases in negative beliefs about treatment and several stigma barriers suggest that ongoing aggregate efforts to destigmatize mental health treatment may be having an impact on National Guard soldiers' perceptions (Greden et al., 2010; Yellow Ribbon Reintegration Program, 2013).

Interestingly, as in prior reports (Hoge et al., 2004), soldiers who had mental health symptoms were more likely to report barriers to mental health care. Potentially, soldiers with symptoms are more likely to be involved with the treatment system and thus, more likely to encounter logistical barriers to care and to consider others' reactions to their treatment (Vogt, 2011). Ongoing efforts to address stigma and treatment belief barriers may need to be pursued even if soldiers have already connected to care, as these barriers could potentially affect their treatment retention.

Study data also indicated that National Guard leadership (officers) may be particularly affected by stigma barriers. Thus, continued efforts to address stigma and ensure that military leaders do not have their careers affected by treatment seeking may be an important area to expand.

Although high rates of stigma among military populations have been noted and a link between stigma barriers and services use suggested, only a few studies have directly examined this (Vogt, 2011). In line with two prior studies in National Guard populations (Kehle et al., 2010), we did not find a clear association between logistical or stigma barriers and treatment receipt among soldiers with mental health symptoms. Congruent with studies by Pietrzak et al., 2009 and Kehle et al., 2010, however, we did find that negative beliefs about treatment were significantly associated with reduced services use. Thus, beliefs about treatment may be particularly important to address if services use is to be increased over time.

\section{Limitations}

There are several methodological issues and limitations that must be considered when interpreting study findings. Data were collected at variable lengths of time following return from overseas deployments, although all data were collected within 6 months of return. Depressive symptoms were measured with the BDI-II at the first time point but with the PHQ-9 at the second and third time points. Response rates to the survey were lower at T1 and T3 compared to T2, falling below 50\%, and surveys were collected both with mail and in group settings at T3 but only in group settings in T1 and T2. Differences in time since return, response rate, and mode of data collection may have affected study findings. We note, however, that covariates were included in study models for soldier demographics across time periods and that some of the most sensitive data collected (i.e., overall reports of mental health symptoms) did not differ significantly by time period of data collection. We also note limitations of our measure of negative beliefs about treatment, which has been widely used, but is based on only two items.

We used repeated cross-sectional samples in this study and cannot comment on changes in individual soldiers' perceptions of barriers over time. Secular trends may also have impacted findings. Future studies should prospectively assess individuals' endorsement of stigma and other treatment barriers and their effects on subsequent services use. Finally, data from this midwestern Guard organization may not generalize to other National Guard organizations.

This report documenting reduced reports of barriers to mental health care related to both negative beliefs about treatment and stigma is a heartening finding, given vigorous efforts by the military community and its partners to address barriers to appropriate care for soldiers with need. Exploratory analyses that indicate that barriers related to negative beliefs about treatment are associated with reduced mental health services use further reinforce the potential importance of these findings. Several logistical barriers and individual stigma-related concerns, however, regarding potential harm to one's career require further attention. Further research is also needed that prospectively examines soldiers' report of barriers to treatment and their subsequent treatment engagement and outcomes.

\section{References}

American Psychiatric Association. (1994). Diagnostic and statistical manual of mental disorders ( $4^{\text {th }}$ ed.). Washington, DC: Author.

Arnau, R. C., Meagher, M. W., Norris, M. P., \& Bramson, R. (2001). Psychometric evaluation of the Beck Depression Inventory-II with primary care medical patients. Health Psychology: Official Journal of the Division of Health Psychology, American Psychological Association, 20(2), 112-119.

Babor, T. F., \& Kadden, R. M. (2005). Screening and interventions for alcohol and drug problems in medical settings: what works? J Trauma, 59(3 Suppl), S80-S87. doi:00005373-200509001-00021[pii]

Beck, A. T., Steer, R. A., \& Brown, G. K. (1996) Manual for the Beck Depression Inventory-II. San Antonio, TX: Psychological Corporation. 
Blanchard, E. B., Jones Alexander, J., Buckley, T. C., \& Forneris, C. A. (1996) Psychometric properties of the PTSD Checklist (PCL). Behaviour Research and Therapy, 34, 669-673. doi:10.1016/0005-7967(96)00033-2

Bliese, P. D., Wright, K. M., Adler, A. B., Cabrera, O., Castro, C. A., \& Hoge, C. W. (2008). Validating the primary care posttraumatic stress disorder screen and the posttraumatic stress disorder checklist with soldiers returning from combat. J Consult Clin Psychol, 76(2), 272-281. doi:2008-03290009[pii]10.1037/0022-006X.76.2.272

Bowles, S. V., \& Bates, M. J. (2010). Military organizations and programs contributing to resilience building. Military Medicine, 175, 382-385. doi:10.7205/MILMED-D-10-00099

Bradley, K. A., DeBenedetti, A. F., Volk, R. J., Williams, E. C., Frank, D., \& Kivlahan, D. R. (2007). AUDIT-C as a brief screen for alcohol misuse in primary care. Alcoholism: Clinical Experimental Research, 31, 1208-1217. doi:10.1111/j.1530-0277.2007.00403.x

Britt, T. W. (2000). The stigma of psychological problems in a work environment: Evidence from the screening of service members returning from Bosnia. Journal of Applied Social Psychology, 30, 1599-1618. doi:10.1111/j.1559-1816.2000.tb02457.x

Cochran, W. G. (1954). Some methods for strengthening the common $\chi 2$ tests. Biometrics, 10, 417-451. doi:10.2307/3001616

Cornum, R., Matthews, M. D., \& Seligman, M. E. P. (2011). Comprehensive soldier fitness: Building resilience in a challenging institutional context. The American Psychologist, 66, 4-9. doi:10.1037/a0021420

Dawson, D. A., Grant, B. F., Stinson, F. S., \& Zhou, Y. (2005). Effectiveness of the derived Alcohol Use Disorders Identification Test (AUDIT-C) in screening for alcohol use disorders and risk drinking in the US general population. Alcoholism, Clinical and Experimental Research, 29, 844-854. doi:10.1007/s11606-008-0594-0

Dillman, D. A., Smyth, J. D., \& Christian, L. M. (2009). Internet, mail, and mixed-mode survey: The tailored design method. Hoboken, NJ: Wiley.

Gorman, L. A., Blow, A. J., Ames, B. D., \& Reed, P. L. (2011). National Guard families after combat: Mental health, use of mental health services, and perceived treatment barriers. Psychiatric Service, 62, 28-34. doi:10.1176/appi.ps.62.1.28

Greden, J. F., Valenstein, M., Spinner, J., Blow, A., Gorman, L. A., Dalack, G. W., ... Kees, M. (2010). Buddy-to-Buddy, a citizen soldier peer support program to counteract stigma, PTSD, depression, and suicide. Annals of the New York Academy of Sciences, 1208, 90-97. doi:10.1111/j.17496632.2010.05719.x

Hoge, C. W., Castro, C. A., Messer, S. C., McGurk, D., Cotting, D. I., \& Koffman, R. L. (2004). Combat duty in Iraq and Afghanistan, mental health problems, and barriers to care. New England Journal of Medicine, 351, 13-22. doi:10.1056/NEJMoa040603

Kehle, S. M., Polusny, M. A., Murdoch, M., Erbes, C. R., Arbisi, P. A., Thuras, P., \& Meis, L. A. (2010). Early mental health treatment-seeking among U.S. National Guard soldiers deployed to Iraq. Journal of Traumatic Stress, 23, 33-40. doi:10.1002/jts.20480

Kim, P. Y., Thomas, J. L., Wilk, J. E., Castro, C. A., \& Hoge, C. W. (2010). Stigma, barriers to care, and use of mental health services among active duty and National Guard soldiers after combat. Psychiatric Services, 61, 582-588. doi:10.1176/appi.ps.61.6.582

Kroenke, K., Spitzer, R. L., \& Williams, J. B. (2001). The PHQ-9: Validity of a brief depression severity measure. Journal of General Internal Medicine, $16,606-613$.

Milliken, C. S., Auchterlonie, J. L., \& Hoge, C. W. (2007). Longitudinal assessment of mental health problems among active and reserve component soldiers returning from the Iraq war. Journal of the American Medical Association, 298, 2141-2148. doi:10.1001/jama.298.18.2141
National Guard Bureau. (n.d.). 2012 National Guard Bureau Posture Statement. Retrieved from http://www.nationalguard.mil/portals/31/ Documents/PostureStatements/2012\%20National\%20Guard\%20Bureau $\%$ 20Posture\%20Statement.pdf

Olfson, M., Marcus, S. C., Druss, B., Elinson, L., Tanielian, T., \& Pincus, H. (2002). National trends in the outpatient treatment of depression. Journal of the American Medical Association, 287, 203-209. doi:10.1001/jama.287.2.203

O'Neil, C. (2012, February 14). Changing of the Guard: A look back at 10 years of war. [Investigative project]. Retrieved from http://hiddensurge.nationalsecurityzone.org/nsjihs_special_pages/changingof-the-guard/

Pfeiffer, P. N., Szymanski, B. R., Valenstein, M., McCarthy, J. F., \& Zivin, K. (2012). Trends in antidepressant prescribing for new episodes of depression and implications for health system quality measures. Medical Care, 50, 86-90. doi:10.1097/MLR.0b013e3182294a3b

Pietrzak, R. H., Johnson, D. C., Goldstein, M. B., Malley, J. C., \& Southwick, S. M. (2009). Perceived stigma and barriers to mental health care utilization among OEF-OIF veterans. Psychiatric Services, 60, 1118-1122. doi:10.1176/appi.ps.60.8.1118

Reinert, D. F., \& Allen, J. P. (2007). The Alcohol Use Disorders Identification Test: An update of research findings. Alcoholism: Clinical and Experimental Research, 31, 185-199. doi:10.1111/j.1530-0277.2006. 00295. $\mathrm{x}$

Riviere, L. A., Kendall-Robbins, A., McGurk, D., Castro, C. A., \& Hoge, C. W. (2011). Coming home may hurt: Risk factors for mental ill health in US reservists after deployment in Iraq. British Journal of Psychiatry, 198, 136-142. doi:10.1192/bjp.bp.110.084863

Schneider, A. T., Pancioli, A. M., Khoury, J. C., Rademacher, A., Tuchfarber, A., Miller, R., ... Broderick, J. (2003). Trends in community knowledge of the warning signs and risk factors for stroke. Journal of the American Medical Association, 289, 343-346. doi:10.1001/jama.289.3.343

Seal, K. H., Maguen, S., Cohen, B., Gima, K. S., Metzler, T. J., Ren, L., ... Marmar, C. R. (2010). VA mental health services utilization in Iraq and Afghanistan veterans in the first year of receiving new mental health diagnoses. Journal of Traumatic Stress, 23, 5-16. doi:10.1002/jts.20493

Steer, R. A., \& Clark, D. A. (1997). Psychometric characteristics of the Beck Depression Inventory-II with college students. Measurement and Evaluation in Counseling and Development, 30(3), 128-136.

Tanielian, T., \& Jaycox, L. H. (2008). Invisible wounds of war: Psychological and cognitive injuries, their consequences, and services to assist recovery. Santa Monica, CA: RAND.

Thomas, J. L., Wilk, J. E., Riviere, L. A., McGurk, D., Castro, C. A., \& Hoge, C. W. (2010). Prevalence of mental health problems and functional impairment among active component and National Guard soldiers 3 and 12 months following combat in Iraq. Archives of General Psychiatry, 67, 614-623. doi:10.1001/archgenpsychiatry.2010.54

Vogt, D. (2011). Mental health-related beliefs as a barrier to service use for military personnel and veterans: A review. Psychiatric Services, 62, 135142. doi:10.1176/appi.ps.62.2.135

Weathers, F. W., Litz, B. T., Herman, D. S., Huska, J. A., \& Keane, T. M. (1993, October). The PTSD Checklist (PCL): Reliability, validity, and diagnostic utility. Paper presented at the annual meeting of the International Society for Traumatic Stress Studies, San Antonio, TX.

Wright, K. M., Cabrera, O. A., Bliese, P. D., Adler, A. B., Hoge, C. W., \& Castro, C. A. (2009). Stigma and barriers to care in soldiers postcombat. Psychological Services, 6, 108-116. doi:10.1037/a0012620

Yellow Ribbon Reintegration Program. (2013, February). Retrieved from http://www.yellowribbon.mil/ 